\title{
Article \\ Personalizing Environmental Awareness through Smartphones Using AHP and PROMETHEE II
}

\author{
Akrivi Krouska $^{1}$ D, Katerina Kabassi ${ }^{2}$, Christos Troussas ${ }^{1, *} \mathbb{D}$ and Cleo Sgouropoulou ${ }^{1}$ \\ 1 Department of Informatics and Computer Engineering, University of West Attica, 12243 Aigaleo, Greece; \\ akrouska@uniwa.gr (A.K.); csgouro@uniwa.gr (C.S.) \\ 2 Department of Environment, Ionian University, 49100 Corfu, Greece; kkabassi@ionio.gr \\ * Correspondence: ctrouss@uniwa.gr
}

Citation: Krouska, A.; Kabassi, K.; Troussas, C.; Sgouropoulou, C. Personalizing Environmental Awareness through Smartphones Using AHP and PROMETHEE II. Future Internet 2022, 14, 66. https:// doi.org/10.3390/fi14020066

Academic Editors: Salvatore Carta and Fotis Liarokapis

Received: 31 January 2022

Accepted: 19 February 2022

Published: 21 February 2022

Publisher's Note: MDPI stays neutral with regard to jurisdictional claims in published maps and institutional affiliations.

Copyright: (C) 2022 by the authors. Licensee MDPI, Basel, Switzerland. This article is an open access article distributed under the terms and conditions of the Creative Commons Attribution (CC BY) license (https:/ / creativecommons.org/licenses/by/ $4.0 /)$.

\begin{abstract}
Environmental awareness refers to the understanding of the importance of protecting the natural environment. Digital technologies can play an important role in raising awareness of environmental issues. In view of this compelling need, this paper presents a novel way to promote environmental awareness with the use of smartphones. To achieve this, it employs personalization techniques, and specifically the Analytic Hierarchy Process (AHP) and PROMETHEE II. In more detail, the mobile application incorporates a user model that holds information, such as location (city, mountain, sea, etc.), age, interests, needs and indicators of waste management, economy of natural resources, general environmental protection, and biodiversity. At the first interaction of the user with the application, the user model is initialized; then, the system uses AHP and PROMETHEE II to provide personalized advice to users in order to help them raise their environmental awareness. The criteria, used to evaluate environmental advice, include the current location, living environment, habits, interests, needs, age, and seasonal suitability of the user. The novelty of this paper is the combination of AHP and PROMETHEE II for personalizing the environmental awareness using mobile technologies, taking into consideration the user profile as well as the surrounding area where the user is at the time that the advice is provided. The presented application has been evaluated regarding the system usefulness and environmental awareness. The findings indicate the high acceptance of this approach and its positive impact on users' attitude and behavior with regard to reducing their environmental footprint.
\end{abstract}

Keywords: environmental awareness; personalized system; Analytic Hierarchy Process; PROMETHEE II; mobile application

\section{Introduction}

Natural resource conservation and environmental protection are now in jeopardy as a result of increased commodity movement by trade and domestic use to satisfy populations' increasing demands [1]. The relationship of economic, social, and environmental metrics is important to understanding the global status of sustainability, according to early claims on environmental sustainability in the literature.

Environmental awareness entails being mindful of the physical environment and making decisions that profit rather than harm the environment. Moreover, climate action is one of the Sustainable Development Goals, which are included in the 2030 Agenda for Sustainable Development (https://sdgs.un.org/2030agenda accessed on 30 January 2022). Using clean and non-toxic construction materials, conserving electricity and water, recycling, campaigning, and other methods are some of the ways to exercise environmental awareness. Indeed, environmental awareness is critical for our daily life [2]. To ensure the planet's long-term viability, everyone must commit to being more environmentally conscious. As such, human activity and environmental behavior on the earth play an important role. Changes in human behavior can help to improve the management and resolution of many environmental problems. A systematic analysis has accumulated a pool of 
information about the importance of effective management of natural resources, ecosystem services, and the reasons why adult people need to take environmental conservation into serious consideration [3]. Environmentally responsible and conscious adults can only come from environmentally conscious young people. However, young people's attitudes and perceptions of the environment are partially limited. Furthermore, understanding of the factors that affect the environmental behavior of young people is minimal. People who work with the biological facets of the natural world and acquire knowledge in close proximity to nature have a strong desire to conserve valuable natural resources. When people have frequent interactions with nature, they have a better understanding of natural mechanisms and habitats. Furthermore, new findings show that young people's exposure to nature affects their environmental consciousness and attitudes toward the natural world [4].

Taking advantage of recent technological and scientific advances to provide accurate environmental data readily available to all citizens is a solution to the rapid deterioration of our natural world caused by human activity. New programming techniques for decision making and data sharing have emerged in the scientific world [5]. As environmental issues have led to increased environmental awareness around the world in recent decades, an ever-growing culture in science has developed new computer technologies for sharing knowledge in the field of environmental protection.

In terms of the above, information and communication technologies have emerged as one of the most prominent means of global knowledge exchange. People from all over the world can read information from different outlets. Any customized information recommendation platforms provide a vast number of online users with personalized recommendation services [6]. As a result, these systems have amassed a sizable user base, and they can create much more value than those that either do not or have a low customized advisory framework. Helping people discover informative stories that fit their preferences as closely as possible has been one of the biggest obstacles for modern internet media websites and smartphone apps. To achieve this, these applications entail the incorporation of algorithms and artificial intelligence, considering the human-algorithm complex duality [7].

Analyzing the related literature, the majority of authors have mainly focused on three categories: (i) theoretical perspectives on environmental awareness, (ii) measurement of people's environmental concern, and (iii) employing digital technologies for raising environmental awareness $[1,2,4,5,8-30]$. For the third category in particular, the authors used mobile learning tools, digital games, social media, recommender systems, educational robotics, digital storytelling tools, and extended reality to raise awareness about environmental issues. Other works presented user engagement methodologies in environmental education for awareness. In two recent studies [31,32], it was emphasized that the need to develop software to increase people's awareness of environmental issues is still profound. However, based on the above works, the authors have not incorporated sufficiently intelligent techniques to further promote the environmental awareness of people by offering a user-centered experience to them.

Kabassi and Martinis [5] have employed a multi-criteria decision-making (MCDM) method to build a recommender system. MCDM is a decision support methodology which is used to improve the credibility and reliability of the selected solution. MCDM aims to help the decision makers to find an optimal solution in accordance with the criteria in question, as for example in [33-37]. Analytic Hierarchy Process (AHP) [38,39] is one of the most popular MCDM theories, focusing on organizing and analyzing complex decisions; it provides a logical framework for a specific decision by quantifying its alternative options and criteria.

In this paper, we show how AHP (Analytic Hierarchy Process) [37] can be effectively combined with PROMETHEE II (Preference Ranking Organization METHod for Enrichment Evaluations II) $[40,41]$ in a mobile application to further promote environmental awareness of users by offering personalized feedback to them based on their residence, habits, needs, age, and season. 
Selecting AHP over other MCDM methods is a simple process since it offers a validated way of quantifying the qualitative criteria of the alternatives and thus eliminates the subjectivity of the result [42]. However, in this method the pairwise comparison of options is quite complex; this method is not chosen in cases where the number of alternatives is large. Hence, AHP was chosen to be combined with PROMETHEE II. In more detail, PROMETHEE method is easy to use, software driven, offers an undeviating interpretation of parameters, and analyzes the sensitivity of results. PROMETHEE II is an excellent method for ranking and selecting among a limited set of alternative actions while observing several conflicting criteria [43]. Additionally, PROMETHEE II outranking method was embraced in this system to evaluate the alternative advice created by the system on the basis of the criteria acquired by the user model, rank the alternatives, and select the one with the higher value.

In view of the above, we present how AHP can be utilized for calculating the weights of criteria and then combined with PROMETHEE II for evaluating and selecting the alternative proposal/advice that better fits the interests and needs of the user interacting with the system. It needs to be noted that the combination of AHP with PROMETHEE II has been effectively used in different domains (e.g., [44-46]), but never before for providing personalized advice for environmental awareness.

In light of the foregoing, the scope of this paper is to combine AHP and PROMETHEE II to promote the environmental awareness of users in a personalized way through a smartphone. The mobile application holds a user model with information, such as place of living (e.g., urban, mountain, sea, etc.), age and indexes of waste management, economy of natural resources, general environmental protection, and biodiversity. With the input of the user model, the system employs AHP and PROMETHEE II to deliver advice to users toward raising their environmental awareness. The criteria that are taken into account while evaluating environmental advice include the compatibility of users' current location, environment of residence, habits, interests, needs, age, and season. The mobile application was evaluated, and the results show a high degree of usability, acceptance, and positive impact on users' consciousness regarding environmental issues.

\section{Initialization of the User Model}

The user in his/her first interaction with the system must answer some questions that will initialize the user model regarding issues that are related to waste management, economy of natural resources, environmental protection, biodiversity, etc. The questions should not be onerous. As such, the questions that belong in the initial questionnaire are (indicatively):

a. Where do you live?

i. Urban

ii. Sea

iii. Mountain

iv. River

v. Lake

vi. Country

b. How old are you?

c. Are you used to:

i. smoking?

ii. outdoor activities?

iii. driving instead of using public transportation?

d. Do you participate in environmental conservation volunteer programs?

e. How willing are you to change your lifestyle to reduce the damage you cause to the environment?

f. Do you recycle? (index for waste management) 
g. Are you meticulous in turning off the lights when you leave a room? (index for economy of natural resources)

h. Do you pick up your trash when you leave the beach or after a picnic? (index for general environmental protection)

i. Are you interested in the flora and fauna of your area? (index for biodiversity)

\section{Defining MCDM Based on User Model}

\subsection{Description of Criteria}

The main characteristic of an MCDM model is that every alternative action is evaluated on the basis of several, often contradicting, criteria. These criteria are not equally important in the reasoning process of selecting which action seems better. Therefore, a weight of importance is calculated for each criterion. The multi-criteria decision-making methods differ in how the criteria weights are computed; however, many methods do not employ a predefined method for the calculation of the weights of criteria. For example, PROMETHEE II does not employ a well-defined means for the calculation of the criteria's weights. On the other hand, AHP has a very well-defined method for calculating the weights of criteria and as such the particular MCDM theory is used in the following steps.

After having defined the main goal of the MCDM evaluation, which, in our system, is to evaluate the alternative pieces of advice and select the one that seems to fit better to the interests and needs of a user in order to help him/her reduce his/her environmental footprint, the next step involves setting the set of criteria.

In order to define the criteria that are taken into consideration while evaluating environmental advice, and since the set of criteria had not been formed before in a similar system, we conducted an empirical study. In this study, six environmental experts (two experts in sustainable development and biodiversity, two experts in waste management, and two experts in climate change) participated, and the criteria that all experts agreed were essential for evaluating the alternative advice are presented below:

1. C1: Compatibility of current location: the system checks if the location of user is in urban environment, sea, mountain, river, lake, or plain country and searches the:

a. Compatibility of subject with urban environment

b. Compatibility of subject with sea

c. Compatibility of subject with mountain

d. Compatibility of subject with river

e. Compatibility of subject with lake

f. Compatibility of subject with plain country

In view of the above, the compatibility of the subject with the current location of the user is calculated as a value to this criterion. The values are $0<\mathrm{C} 1<1$.

2. C2: Compatibility with the environment of residence: Checks whether the subject is compatible with the environment where the user's home is. The value of this criterion is very high if the user is at home and low if the user is away from home. A subject concerning the environment where $\mathrm{s} /$ he lives is very important and must not be overlooked, but if $\mathrm{s} /$ he is away from home, it is possible that other subjects have higher priority in the particular moment.

3. C3: Compatibility with user's habits: This criterion reveals whether the alternative advice is compatible with the user's habits as these are stored in the user model. For example, a piece of advice that is relevant to waste management is higher if the user already has some habits related to this, e.g., s/he recycles.

4. C4: Compatibility with user's interests: This criterion reveals whether the alternative advice is compatible with the user's interests as these are stored in the user model.

5. C5: Compatibility with user's needs: This criterion reveals whether the alternative advice is compatible with the user's needs as these are stored in the user model. For example, the user model reveals that there is great need for economy in natural resources, so the value of this criterion is higher for advice related to this need. 
6. C6: Compatibility with age: Users, according to the six human experts, were categorized into four age groups:
a. $<18$
b. $18-30$
c. $31-60$
d. $>61$

The value of this criterion shows the compatibility of the alternative advice with the age group of the user.

7. C7: Compatibility with season: This criterion shows whether the piece of advice is compatible with the current season or the current month.

\subsection{AHP for Calculating Weights of Criteria}

AHP seeks to analyze a qualitative problem through a quantitative method. According to [47], after having developed the goal hierarchy, in order to apply AHP, the pair-wise comparison matrix of criteria has to be set up. In applying AHP, first, the set of evaluators has to be formed, acting as decision-makers in the application of AHP for the calculation of the weights of criteria. In fact, selecting an expert correctly would provide valid and reliable results. As a result, domain experts and software engineers have been chosen to participate in the experiment to improve the reliability of the results. Regarding domain experts, they were environmentalists and ecologists. Specifically, the six human experts that participated in the first phase as well as two software engineers and two experts in user modeling were asked to conduct the pairwise comparisons of criteria.

The steps that need to be implemented are:

(1) Setting up a pair-wise comparison matrix of criteria: In this step, a comparison among the criteria of the same level is conducted. For this reason, a comparison matrix is created, and each decision-maker was asked to fill in the comparison matrix by adding the frequency that reveals that pairwise comparison of the criterion in the row with the criterion in the column. They are invited to use the values of the nine-point scale for the pairwise comparison as presented in Table 1.

Table 1. The nine-point scale for pairwise comparison.

\begin{tabular}{ccc}
\hline Importance & Definition & Explanation \\
1 & Equivalent Importance & Both criteria are equally important. \\
3 & Average Importance & A small advantage of one criterion \\
4 & Extra Average & over another. \\
5 & High Importance & Strong advantage of one criterion \\
6 & Extra High & over another. \\
7 & Very High Importance & $\begin{array}{r}\text { Very strong advantage of one } \\
\text { criterion over another. }\end{array}$ \\
8 & Very, Very High & A criterion is certainly more favored \\
than another criterion.
\end{tabular}

Thereby, six different matrixes were collected. The values in the cells of the final matrix are computed as an average of the corresponding values of the cells of the six matrixes. Table 2 presents the final pair-wise comparison matrix of criteria.

(2) Calculating weights of criteria: After performing pair-wise comparisons, estimations are made resulting in the final set of weights of the criteria. For simplicity, the 'Priority Estimation Tool' (PriEst) [48] has been used, which is an open-source decision-making software that implements AHP, to perform calculations for the theory (Figure 1). 
Table 2. Pairwise comparison of criteria.

\begin{tabular}{cccccccc}
\hline Criteria & C1 & C2 & C3 & C4 & C5 & C6 & C7 \\
\hline C1: Compatibility of current location & 1.00 & 5.50 & 1.06 & 0.35 & 2.25 & 0.75 & 2.00 \\
C2: Compatibility with residence environment & 0.20 & 1.00 & 0.33 & 0.42 & 0.42 & 1.50 & 3.00 \\
C3: Compatibility with user's habits & 4.25 & 3.00 & 1.00 & 1.17 & 1.63 & 1.75 & 1.13 \\
C4: Compatibility with user's interests & 3.50 & 2.50 & 1.75 & 1.00 & 1.75 & 2.67 & 2.17 \\
C5: Compatibility with user's needs & 1.13 & 2.50 & 2.17 & 1.17 & 1.00 & 3.13 & 3.75 \\
C6: Compatibility with age & 1.50 & 0.75 & 1.17 & 1.60 & 2.08 & 1.00 & 3.50 \\
C7: Compatibility with season & 0.50 & 0.38 & 2.25 & 1.63 & 1.07 & 0.29 & 1.00 \\
\hline
\end{tabular}

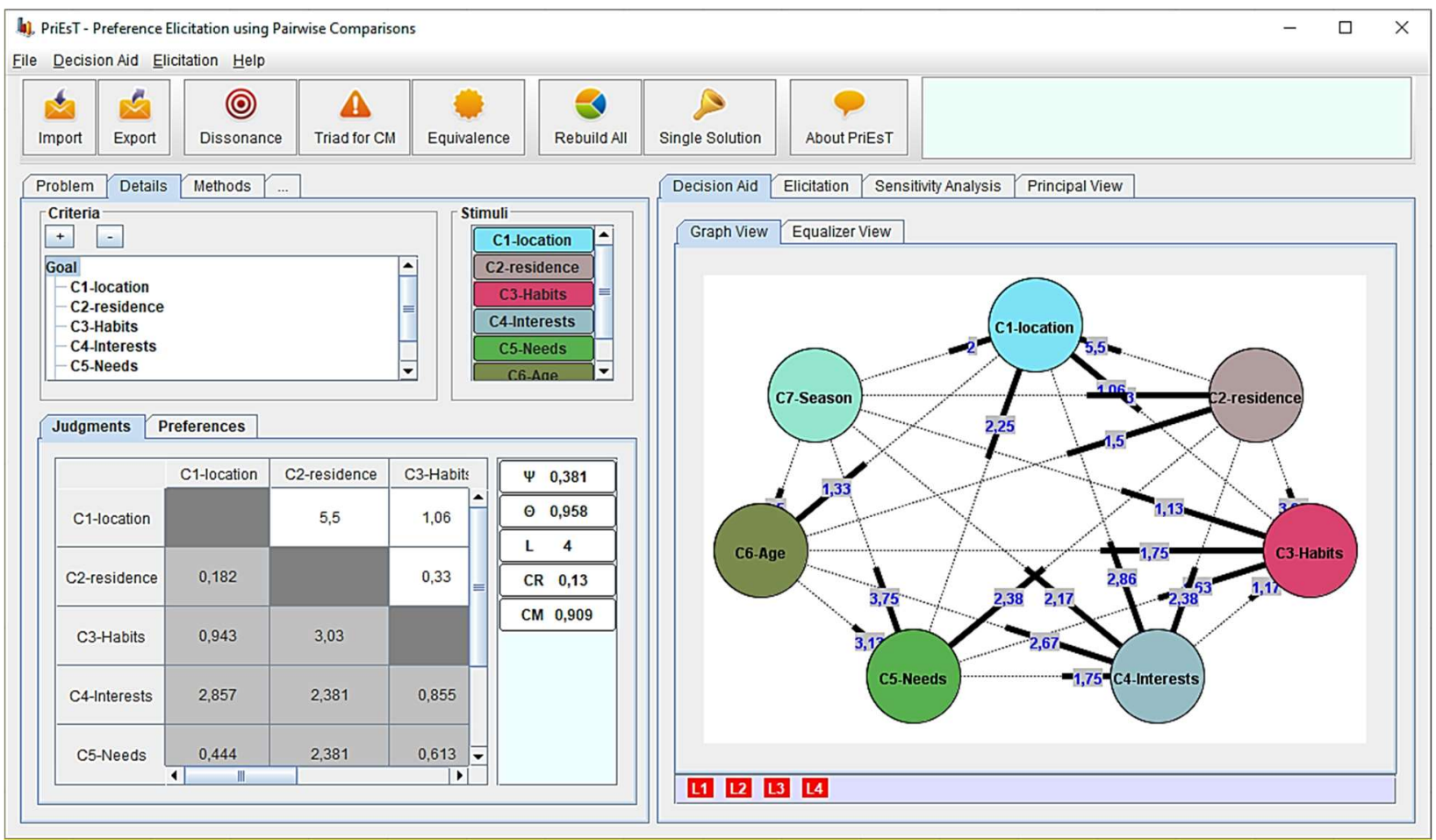

Figure 1. PriEst calculating weights.

This process resulted in the following weights for the ten criteria evaluated:

- $\quad \mathrm{C} 1$ : Compatibility of current location $\rightarrow w_{c 1}=0.172$

- $\quad$ C2: Compatibility with the environment of residence $\rightarrow w_{c 2}=0.084$

- $\quad$ C3: Compatibility with user's habits $\rightarrow w_{c 3}=0.183$

- C4: Compatibility with user's interests $\rightarrow w_{c 4}=0.234$

- C5: Compatibility with user's needs $\rightarrow w_{c 5}=0.161$

- C6: Compatibility with age $\rightarrow w_{c 6}=0.105$

- $\quad$ C7: Compatibility with season $\rightarrow w_{c 7}=0.061$

\section{Personalized Advice Delivery Using PROMETHEE II}

In this paper, we use PROMETHEE II to evaluate the alternative advice created by the system on the basis of the criteria acquired by the user model, rank the alternatives, and select the one with the higher value. The latter advice is the one that seems to fit the characteristics of the particular user better than the others.

The steps of PROMETHEE II after having defined the criteria and their weights of importance are:

(1) Calculating the values of the criteria. In this step, the evaluator, which in our case is the system, assigns values to all criteria. For this purpose, the system uses information acquired by the user's smartphone (e.g., location, season, etc.) as well as the user model of 
the user interacting with the system. The user model contains information about the users' interests, needs, habits, etc.

(2) Making comparisons and calculating the preference degree. This step computes, for each pair of possible pieces of advice and each criterion, the value of the preference degree. Let $g_{j}(a)$ be the value of a criterion $j$ for an advice $a$. The preference functions $P_{j}(a, b)$ used to compute these preference degrees are:

$$
\begin{gathered}
P_{j}(a, b)=0, \text { if } d_{j}(a, b)<0 \\
P_{j}(a, b)=d_{j}(a, b), \text { if } d_{j}(a, b)>0
\end{gathered}
$$

taking into account that $d_{j}(a, b)=g_{j}(a)-g_{j}(b)$ is the difference of the value of a criterion $j$ for advice $a$ and $b$.

(3) Aggregating the preference degrees of all criteria for pair-wise decisions. This step consists of aggregating the preference degrees of all criteria for each pair of possible pieces of advice:

$$
\pi(a, b)=\left[\sum_{j=1}^{n} w_{j} P_{j}(a, b)\right] / \sum_{j=1}^{n} w_{j}
$$

(4) Calculating positive and negative outranking flow. This step, which is the first that concerns the ranking of the possible decisions, consists of computing the outranking flows. For each possible decision a, we compute the positive outranking flow $\varphi^{+}(\alpha)$ and the negative outranking flow $\varphi^{-}(\alpha)$ as follows:

$$
\begin{aligned}
\varphi^{+}(\alpha) & =\frac{1}{m-1} \sum_{b=1}^{m} \pi(\alpha, b) \text { when } \alpha \neq b \\
\varphi^{-}(\alpha) & =\frac{1}{m-1} \sum_{b=1}^{m} \pi(b, a) \text { when } \alpha \neq b
\end{aligned}
$$

(5) Calculating the net outranking flow. The ranking is based on the net outranking flow $\varphi(\alpha)$ of a possible decision a, computed as follows: $\varphi(\alpha)=\varphi^{+}(\alpha)-\varphi^{-}(\alpha)$. The higher the value $\varphi(\alpha)$ is, the better the advice is. The advice that has the highest value of $\varphi(\alpha)$ is selected to be proposed to the user.

\section{Evaluation}

\subsection{Examples of Operation}

For better understanding of the functionality of personalizing environmental awareness though the developed mobile application, a representative example is provided in this section, based on the system's log files. The example presents the case of three users who live in the urban area, belong to the same age group (20-24 years), and were found at the beach in the summer season (the beach, which each user visited, was in different places and the event took place the first week of August). Regarding the user profiles, User1 and User2 smoke, while User3 does not. User2 and User3 prefer outdoor activities, in contrast with User1. Moreover, User1 participates in environmental conservation volunteer programs and has been characterized by high index for waste management and general environmental protection. On the other hand, User2 and User3 are not involved in environmental volunteering and have low index for waste management and general environmental protection. Considering the above data, although the context is the same (the beach in summer), the application provided diversified advice tailored to each user model. In particular, User1 received the advice "Help those around you to keep the beach clean! Remind them to pick up their trash", User2 received the advice "Don't forget to throw the cigarette butts into a portable ashtray! Never get rid of them in the sea or sand" and User3 received the advice "Don't forget to pick up your garbage! Prefer reusable packages for your food and drink". Table 3 illustrates the sample data. 
Table 3. Log files of examples of operation.

\begin{tabular}{|c|c|c|c|}
\hline $\begin{array}{l}\text { User Model } \\
\text { Characteristics }\end{array}$ & & User Data & \\
\hline User & User1 & User2 & User3 \\
\hline Residential location & Urban & Urban & Urban \\
\hline Age & 24 & 25 & 22 \\
\hline Smoking & Yes & Yes & No \\
\hline Outdoor activities & No & Yes & Yes \\
\hline $\begin{array}{l}\text { Environmental } \\
\text { volunteering }\end{array}$ & Yes & No & No \\
\hline $\begin{array}{c}\text { Index for } \\
\text { waste management }\end{array}$ & High & Low & Low \\
\hline $\begin{array}{c}\text { Index for } \\
\text { environmental protection }\end{array}$ & High & Low & Low \\
\hline $\begin{array}{c}\text { Personalizing } \\
\text { environmental awareness }\end{array}$ & $\begin{array}{l}\text { Help those around } \\
\text { you to keep the } \\
\text { beach clean! } \\
\text { Remind them to pick } \\
\text { up their trash. }\end{array}$ & $\begin{array}{l}\text { Don't forget to throw } \\
\text { the cigarette butts } \\
\text { into a portable } \\
\text { ashtray! Never get rid } \\
\text { of them in the sea } \\
\text { or sand. }\end{array}$ & $\begin{array}{l}\text { Don't forget to pick } \\
\text { up your garbage! } \\
\text { Prefer reusable } \\
\text { packages for your food } \\
\text { and drink. }\end{array}$ \\
\hline
\end{tabular}

\subsection{Methods and Materials}

A user-based evaluation was conducted in order to assess, firstly, the usefulness of the personalized advice provided by the mobile application and, secondly, the effect of the use of this mobile application on users' environmental awareness. The evaluation technique which was used includes two questionnaires in Likert scale format: one about the system's usefulness and another one about attitude and behavior regarding environmental awareness.

The system usefulness questionnaire consists of nine questions regarding the usability, personalization, user satisfaction, and intention to use. All the questions were prepared in a five-point Likert scale, having as response options: 5 "Strongly Agree", 4 "Agree", 3 "Neutral", 2 "Disagree", 1 "Strongly Disagree". Table 4 illustrates the list of the questions used for evaluating the system's usefulness.

Table 4. Survey questions for evaluating system usefulness.

\begin{tabular}{lr}
\hline$\#$ & Question \\
\hline 1 & Overall, I am satisfied with how easy it is to use the application. \\
2 & The interface of the application was pleasant. \\
3 & The advice provided was to the point regarding the place I was in. \\
5 & The advice was compatible with my interests and needs. \\
6 & I found the advice very useful. \\
7 & I enjoyed the application's advice. \\
9 & The application has all the functions and capabilities I expect it to have. \\
& I intend to use the application in future.
\end{tabular}

The environmental awareness questionnaire consists of 15 questions. The questions were grouped into three dimensions of five questions related to sustainable environment, namely the conscious consuming, the reduction of waste and recycling, and the energy saving. All the questions were prepared in Likert form, offering five options as possible responses: 5 "Every time", 4 "Often", 3 "Sometimes", 2 "Rarely", 1 "Never". The question items of this questionnaire are presented in Section 5.4 along with the distribution of the answers. 


\subsection{Population and Data Collection Procedure}

The participants of this study were 120 students, namely 70 undergraduate and 50 postgraduate ones, in the field of computer science in a public university. Furthermore, $56.67 \%$ of them were male and $43.33 \%$ were female. The distribution of participants regarding their age is as follows: $61.67 \%$ of them were $20-24$ years, $13.33 \%$ were $25-29$ years, $15 \%$ were $30-34$ years, and $12 \%$ were 35 years or above. Concerning the mobile IT devices that participants own, all students had a smartphone and $65 \%$ also had a tablet. Table 5 presents the demographic characteristics of the participants in this research.

Table 5. The distribution of participants in the survey regarding demographic characteristics.

\begin{tabular}{ccc}
\hline \multicolumn{2}{c}{ Demographic Characteristics } & Number of Students (\%) \\
\hline Gender & Male & $68(56.67)$ \\
& Female & $52(43.33)$ \\
\hline Age & $20-24$ & $74(61.67)$ \\
& $25-29$ & $16(13.33)$ \\
& $30-34$ & $18(15)$ \\
& $\geq 35$ & $12(10)$ \\
\hline \multirow{2}{*}{ Education Level } & Undergraduate & $70(58.33)$ \\
& Postgraduate & $50(41.67)$ \\
\hline Mobile IT Devices & Smartphone & $120(100)$ \\
& Tablet & $78(65)$ \\
\hline
\end{tabular}

The students which participated in this study used the developed mobile application for a year. The reason for selecting this experiment period was that we wanted the population to have the whole picture of the application, since the season and the different places that one can visit during the different seasons play an important role in the advising procedure. For evaluating the usefulness of the application and user satisfaction, the corresponding questionnaire was delivered to students after completion of the experiment period. Regarding the analysis of the effectiveness of the developed mobile application and namely of personalizing environmental awareness, a pre-test/post-test experiment was conducted in order to examine whether students who use the proposed application improve their environmental awareness. As such, the corresponding questionnaire was delivered to them before the use of the application and after completion of the experiment period. Afterwards, a paired t-test was applied to compare the pre-test and post-test scores. All the questionnaires were delivered via e-mail and the students were requested to fill them online. All the participants answered completely on the surveys, representing a response rate of $100 \%$.

\subsection{Data Analysis and Discussion}

The results evaluating the usefulness of the developed mobile application in relation to the awakening of environmental consciousness, presented in Figure 2, showed students perceived the application to be interesting, enjoyable, easy to use, accessible, and insightful. In particular, a total of $67 \%$ strongly agreed that the application was easy to use, while $78 \%$ of the participants found its interface pleasant. When students were asked about the personalized advice provided, the majority of them $(49.2 \%+30.8 \%=80 \%)$ agreed that the advice was highly related to the place they were in at the time they displayed, and a corresponding remarkable percentage $(47.5 \%+36.7 \%=84.2 \%)$ agreed that the advice was compatible with their interests and needs. These results support the effectiveness of the model used for selecting the most suitable advice regarding the use profile and the overall context. Moreover, $52.5 \%$ of the participants strongly felt that the advice was very useful, while $34.2 \%$ agreed to this statement. It should also be noted that $50.8 \%$ of the students strongly enjoyed the application's advice, while $40.8 \%$ agreed with this statement. Concerning the system's operations, a very high percentage of the participants $(54.2 \%+28.3 \%=82.5 \%)$ agreed that 
the application provided all the functions and capabilities they expected. Furthermore, a total of $83.3 \%$ agreed that they intended to use the application in the future, while $13.3 \%$ chose to be neutral and 3.4\% disagreed with this statement. Similarly, an extremely large group of $89.2 \%$ stated that they would recommend this application to a friend, while $9.2 \%$ declared neutrality and only $1.7 \%$ disagreed with this statement. These findings reflect the user acceptance of the developed application and the positive impact after using the developed mobile application.

9. Surely, I will recommend this application to a friend.

8. I intend to use the application in future.

7. The application has all the functions and capabilities I expect it to have.

6 . I enjoyed the application's advice.

5. I found the advice very useful.

4. The advice was compatible with my interests and needs.

3. The advice provided was to the point regarding the place I was.

2. The interface of the application was pleasant.

1. Overall, I am satisfied with how easy it is to use the application.

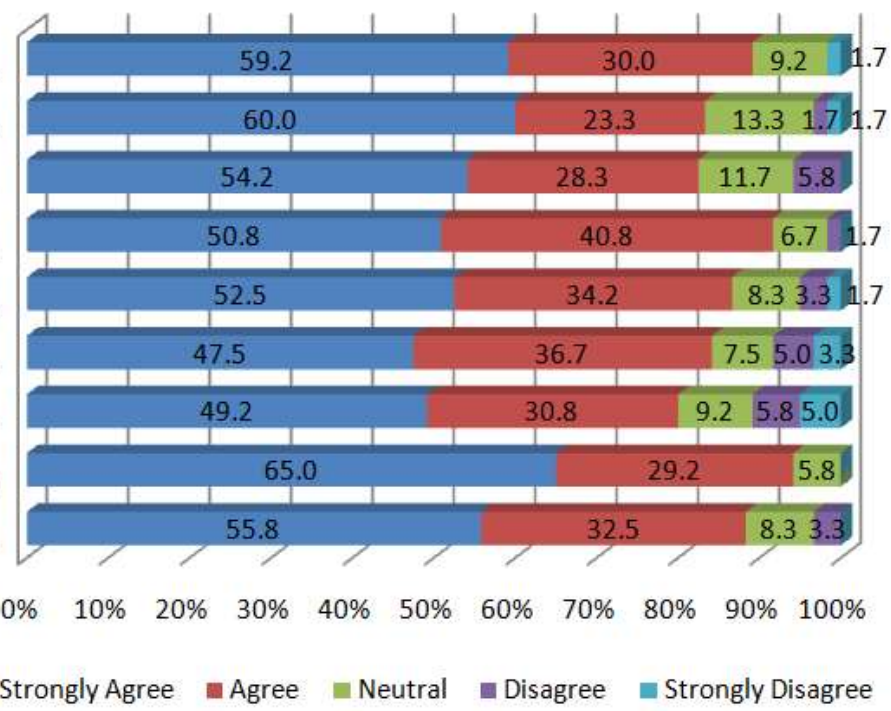

Figure 2. Frequency distribution of the answers regarding system's usefulness.

Tables 6-8 illustrate the frequency distribution of the answers in questions relating to the three environmental dimensions evaluated, namely the conscious consuming, the reduction of waste and recycling, and the energy saving, respectively. They also present the pre-test/post-test results comparing the environmental awareness which emerged from each question of each dimension.

Regarding conscious consuming (Table 5), before the use of the application, the participants rarely or never printed the document on both sides of the paper $(35.83 \%+17.50 \%=53.33 \%)$, while after using the application it is observed that the majority tended to print on both sides of the paper $(25.83 \%+28.33 \%=54.16 \%)$. Moreover, the application fostered participants' preference to send e-mail instead of using hard copy output, since the percentage of "sometimes" option reduced by half $(31.67 \%$ before using the application, $15.83 \%$ after using the application) and the percentages of "every time" and "often" were almost doubled (from $20.83 \%$ and $20.00 \%$ to $41.67 \%$ and $38.33 \%$, respectively). It also seems they stopped printing documents and preferred to read them online, as the answer "every time" was quadrupled and the option "often" was doubled for this statement, while the percentages of options "never" and "rarely" were significantly decreased. The analysis of participants' responses on question 4 shows that a little progress was made concerning the use of reusable foodware; although after using the application a remarkable percentage, namely $21.67 \%+19.17 \%=40.84 \%$, continued to prefer disposable foodware at parties because of the convenience they offer, it should be noted that the corresponding percentage was too high before the application, namely $47.50 \%+24.17 \%=71.67 \%$, while after using the application, the percentages of the preference for reusable foodware were almost tripled (from $5.83 \%+6.67 \%=12.5 \%$ to $14.17 \%+21.67 \%=35.84 \%$ ). Furthermore, the survey reveals that the participants learned more about the refills of products and started to prefer them instead of a complete product (from $10.83 \%+6.67 \%=17.5 \%$ to $40.83 \%+30.83 \%=71.66 \%$ ). According to paired-sample $t$ test comparing the environmental awareness before and after using the application (pre-test awareness $=51.50 \%$, post-test awareness $=72.47 \%$, 
difference $=-20.97)$, the results showed that there was a significant improvement in students' consciousness about consumption of things $(t=-12.043, p<0.05)$.

Table 6. Frequency distribution of the answers and pre-test/post-test results related to conscious consuming.

\begin{tabular}{|c|c|c|c|c|c|c|c|}
\hline \multicolumn{8}{|c|}{ Environmental Awareness Survey: Conscious Consuming } \\
\hline $\begin{array}{l}\text { Pre-Score } \\
\text { Post-Score }\end{array}$ & $\begin{array}{c}5 \\
N(\%)\end{array}$ & $\begin{array}{c}4 \\
N(\%)\end{array}$ & $\begin{array}{c}3 \\
\mathbf{N}(\%)\end{array}$ & $\begin{array}{c}2 \\
N(\%)\end{array}$ & $\begin{array}{c}1 \\
N(\%)\end{array}$ & $\begin{array}{l}\text { Mean } \\
(/ 5)\end{array}$ & $\begin{array}{l}\text { Awareness } \\
\text { (\%) }\end{array}$ \\
\hline \multirow{2}{*}{$\begin{array}{l}\text { 1. I prefer to print the document on } \\
\text { both side of the paper. }\end{array}$} & $11(9.17)$ & $14(11.67)$ & $31(25.83)$ & $43(35.83)$ & $21(17.50)$ & 2.59 & 51.83 \\
\hline & $31(25.83)$ & $34(28.33)$ & $33(27.50)$ & $15(12.50)$ & $7(5.83)$ & 3.56 & 71.17 \\
\hline \multirow{2}{*}{$\begin{array}{l}\text { 2. I prefer to send e-mail instead of } \\
\text { hard copy output. }\end{array}$} & $25(20.83)$ & $24(20.00)$ & $38(31.67)$ & $24(20.00)$ & $9(7.50)$ & 3.27 & 65.33 \\
\hline & $50(41.67)$ & $46(38.33)$ & $19(15.83)$ & $5(4.17)$ & $0(0.00)$ & 4.18 & 83.50 \\
\hline \multirow{2}{*}{$\begin{array}{l}\text { 3. I prefer to read the document on } \\
\text { computer instead of printing it. }\end{array}$} & $8(6.67)$ & $16(13.33)$ & $29(24.17)$ & $39(32.50)$ & $28(23.33)$ & 2.48 & 49.50 \\
\hline & $32(26.67)$ & $33(27.50)$ & $35(29.17)$ & $16(13.33)$ & $4(3.33)$ & 3.61 & 72.17 \\
\hline \multirow{2}{*}{$\begin{array}{l}\text { 4. I prefer to use reusable, instead } \\
\text { of disposable, foodware at parties } \\
\text { and reunions. }\end{array}$} & $7(5.83)$ & $8(6.67)$ & $19(15.83)$ & $29(24.17)$ & $57(47.50)$ & 1.99 & 39.83 \\
\hline & $17(14.17)$ & $26(21.67)$ & $28(23.33)$ & $23(19.17)$ & $26(21.67)$ & 2.88 & 57.50 \\
\hline \multirow{2}{*}{$\begin{array}{l}\text { 5. I prefer to buy refills instead of a } \\
\text { complete product. }\end{array}$} & $13(10.83)$ & $8(6.67)$ & $31(25.83)$ & $48(40.00)$ & $20(16.67)$ & 2.55 & 51.00 \\
\hline & $49(40.83)$ & $37(30.83)$ & $14(11.67)$ & $13(10.83)$ & $7(5.83)$ & 3.90 & 78.00 \\
\hline \multicolumn{7}{|c|}{ Pre-test Mean } & 51.50 \\
\hline \multicolumn{7}{|c|}{ Post-test Mean } & 72.47 \\
\hline \multirow{2}{*}{\multicolumn{7}{|c|}{$\begin{array}{c}\text { Difference } \\
\text { Standard Deviation }\end{array}$}} & -20.97 \\
\hline & & & & & & & 3.894 \\
\hline 3: Sometimes & & \multicolumn{5}{|c|}{$\begin{array}{c}\text { Standard Deviation } \\
\text { Confidence Level (95\%) }\end{array}$} & 4.834 \\
\hline $\begin{array}{l}\text { 2: Rarely } \\
\text { 1. Nezuer }\end{array}$ & & \multicolumn{5}{|c|}{ Pearson Correlation } & 0.917 \\
\hline $\begin{array}{c}\text { 1: Never } \\
N \cdot \text { Numbr of Students }\end{array}$ & & \multicolumn{5}{|c|}{ t Stat } & -12.043 \\
\hline N: Number of Students & & \multicolumn{5}{|c|}{$p$-value } & $2.73 \times 10^{-4}$ \\
\hline
\end{tabular}

Table 7. Frequency distribution of the answers and pre-test/post-test results related to reducing waste and recycling.

\begin{tabular}{|c|c|c|c|c|c|c|c|}
\hline \multicolumn{8}{|c|}{ Environmental Awareness Survey: Reducing Waste and Recycling } \\
\hline $\begin{array}{l}\text { Pre-Score } \\
\text { Post-Score }\end{array}$ & $\begin{array}{c}5 \\
N(\%)\end{array}$ & $\begin{array}{c}4 \\
N(\%)\end{array}$ & $\begin{array}{c}3 \\
N(\%)\end{array}$ & $\begin{array}{c}2 \\
N(\%)\end{array}$ & $\begin{array}{c}1 \\
\text { N }(\%)\end{array}$ & $\begin{array}{l}\text { Mean } \\
(/ 5)\end{array}$ & $\begin{array}{l}\text { Awareness } \\
(\%)\end{array}$ \\
\hline \multirow{2}{*}{$\begin{array}{l}\text { 1. I prefer to use reusable shopping } \\
\text { bags rather than plastic ones. }\end{array}$} & $17(14.17)$ & $16(13.33)$ & $23(19.17)$ & $31(25.83)$ & $33(27.50)$ & 2.61 & 52.17 \\
\hline & $52(43.33)$ & $36(30.00)$ & 17 (14.17) & $10(8.33)$ & $5(4.17)$ & 4.00 & 80.00 \\
\hline \multirow{2}{*}{$\begin{array}{l}\text { 2. I use recycling bins for paper, } \\
\text { plastic, and metal. }\end{array}$} & $18(15.00)$ & $19(15.83)$ & $28(23.33)$ & $41(34.17)$ & $14(11.67)$ & 2.88 & 57.67 \\
\hline & $57(47.50)$ & $31(25.83)$ & $19(15.83)$ & $10(8.33)$ & $3(2.50)$ & 4.08 & 81.50 \\
\hline \multirow{2}{*}{$\begin{array}{l}\text { 3. I use rechargeable batteries } \\
\text { instead of disposable batteries. }\end{array}$} & $5(4.17)$ & $13(10.83)$ & 17 (14.17) & $33(27.50)$ & $52(43.33)$ & 2.05 & 41.00 \\
\hline & $16(13.33)$ & $30(25.00)$ & $33(27.50)$ & $17(14.17)$ & $24(20.00)$ & 2.98 & 59.50 \\
\hline \multirow{2}{*}{$\begin{array}{l}\text { 4. I look for the recycled option in } \\
\text { the products I buy. }\end{array}$} & $4(3.33)$ & $14(11.67)$ & $20(16.67)$ & $27(22.50)$ & $55(45.83)$ & 2.04 & 40.83 \\
\hline & $34(28.33)$ & $35(29.17)$ & $29(24.17)$ & $17(14.17)$ & $5(4.17)$ & 3.63 & 72.67 \\
\hline \multirow{2}{*}{$\begin{array}{l}\text { 5. I throw the garbage into dustbins } \\
\text { before leaving a place. }\end{array}$} & $32(26.67)$ & $38(31.67)$ & $25(20.83)$ & $25(20.83)$ & $0(0.00)$ & 3.64 & 72.83 \\
\hline & $71(59.17)$ & $37(30.83)$ & $12(10.00)$ & $0(0.00)$ & $0(0.00)$ & 4.49 & 89.83 \\
\hline \multicolumn{7}{|c|}{ Pre-test Mean } & 52.9 \\
\hline \multicolumn{7}{|c|}{ Post-test Mean } & 76.7 \\
\hline \multicolumn{7}{|c|}{ Difference } & -23.8 \\
\hline \multicolumn{7}{|c|}{ Standard Deviation } & 6.229 \\
\hline \multicolumn{7}{|c|}{ Confidence Level (95\%) } & 7.735 \\
\hline \multicolumn{7}{|c|}{ Pearson Correlation } & 0.884 \\
\hline \multirow{2}{*}{\multicolumn{7}{|c|}{$\begin{array}{l}\text { 1: Never } \\
\text { N: Number of Students }\end{array}$}} & -8.543 \\
\hline & & & & & & & $1.03 \times 10^{-3}$ \\
\hline
\end{tabular}


Table 8. Frequency distribution of the answers and pre-test/post-test results related to energy saving.

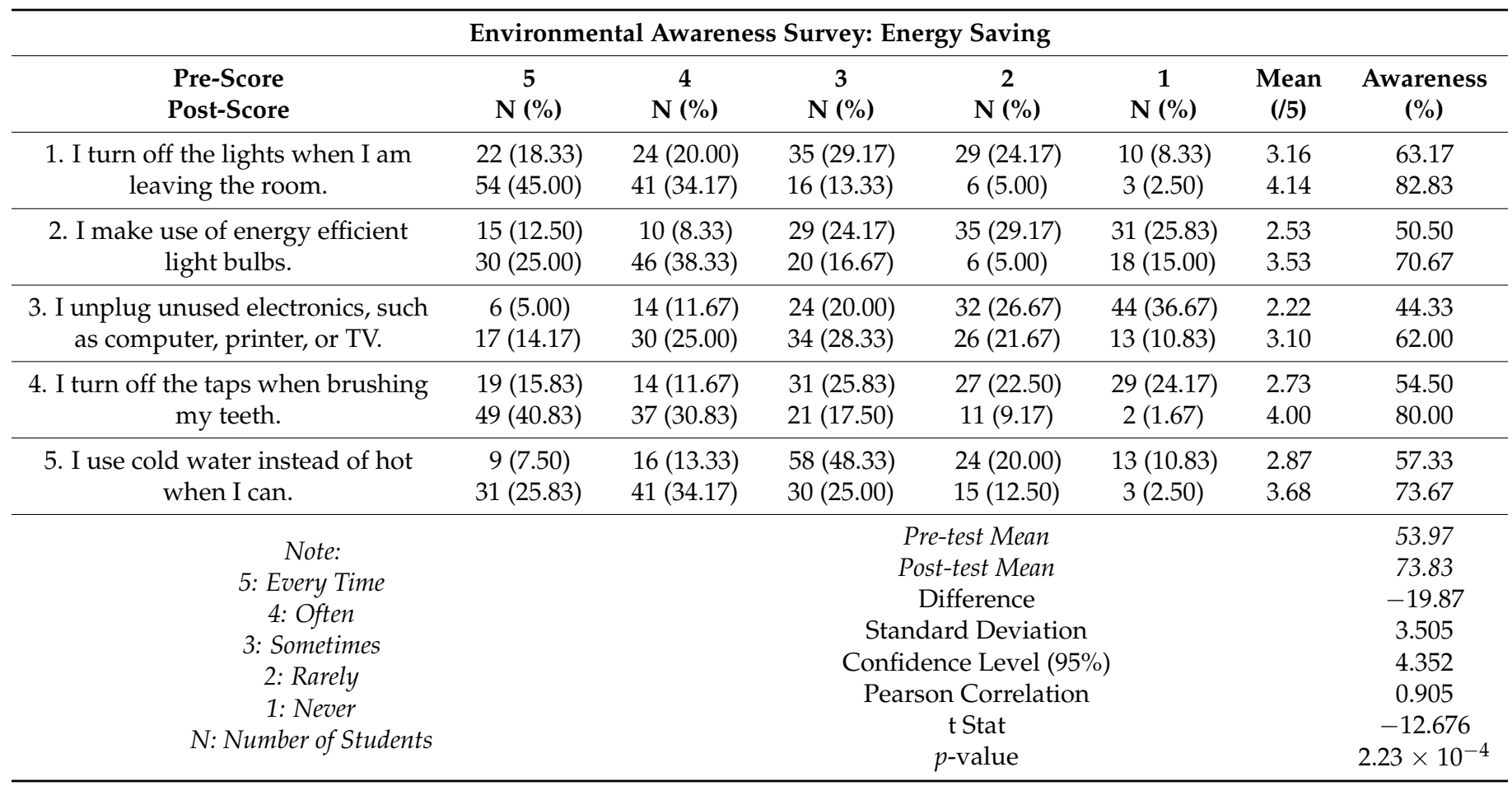

Concerning the environmental awareness survey on reducing waste and recycling (Table 7), participants' behavior indicates that after the use of the application the majority stopped using plastic shopping bags, preferring the reusable ones ("every time": from $14.17 \%$ to $43.33 \%$, "often": from $13.33 \%$ to $30.00 \%$ ). Moreover, a change was made in the habit of recycling paper, plastic, and metal using corresponding bins. Before the application the students sometimes $(23.33 \%)$ or rarely $(34.17 \%)$ did so, and after the application these percentages were reduced to $15.83 \%$ and $8.33 \%$, respectively, while a significant improvement was observed in the frequency of this habit, namely "every time": $47.50 \%$ and "often": $25.83 \%$. At lower rates, there was a trend in use of rechargeable batteries every time (from $4.17 \%$ to $13.33 \%$ ) or often (from $10.83 \%$ to $25.00 \%$ ). This low increase may be due to the need to procure a suitable adapter; however, the percentages of the participants who never or rarely use rechargeable batteries were reduced by half ("never": from $43.33 \%$ to $20.00 \%$, "rarely": from $27.50 \%$ to $14.17 \%$ ). Moreover, it should be noted that participants' market behavior was changed, since after using the application they looked every time $(28.33 \%)$ or often $(29.17 \%)$ for a recycled option for the products they bought, in comparison to their behavior before the application, when almost the majority of them never did so (before: $45.83 \%$, after: $4.17 \%$ ). The application also seems to have improved the participants' habits around picking up their garbage when leaving a place, as the percentage of the option "every time" was doubled (from $26.67 \%$ to $59.17 \%$ ). In total, the paired-sample t-test results on pre-test/post-test environmental awareness emerged from each question evaluating the reduction of waste and recycling indicated that the application had a significant effect on the improvement of students' attitude and behavior in regard to the environment subject (pre-test awareness $=52.9 \%$, post-test awareness $=76.7 \%$, difference $=-23.8, \mathrm{t}=-8.543$, $p<0.05)$.

Pertaining to energy saving (Table 8), the analysis of students' responses showed that great progress was made with respect to the habit of turning off the lights when leaving the room. In particular, the percentage of "every time" or "often" doing so reached $45.00 \%$ and $34.17 \%$, an increase of $18.33 \%$ and $20.00 \%$ respectively, compared to before using the application. Moreover, the advice provided to participants seems to have affected their attitude toward the use of energy efficient light bulbs ("every time": increased from $12.50 \%$ 
to $25.00 \%$, "often": from $8.33 \%$ to $38.33 \%$ ). Before using the application, the majority of students $(36.67 \%+26.67 \%=63.34 \%)$ never or rarely unplugged unused electronics, such as computer, printer, or TV. This fact changed with the application, since it was now observed that students' awareness on this statement reached $62.00 \%$, versus $44.33 \%$ before the application's use. Furthermore, the bad habit of keeping on the taps while brushing one's teeth $(24.17 \%$ and $22.50 \%$ never or rarely turning them off) seemed to break, as the vast majority of participants now turned them off (40.83\% "every time" and 30.83\% "often"). It is worth mentioning that, after using the application, participants mainly preferred to use cold water instead of hot when they could, putting less pressure on electricity grids ("every time": from $7.50 \%$ to $25.83 \%$, "often": from $13.33 \%$ to $34.17 \%$ ). Comparing pre-test and post-test students' awareness on energy saving using the paired-sample t-test, the findings revealed a significant improvement of their consciousness level related to energy saving (pre-test awareness $=53.97 \%$, post-test awareness $=73.83 \%$, difference $=-19.868$, $\mathrm{t}=-12.676, p<0.05)$.

The presented mobile application was developed in order to engage users on environmental sustainability. The system introduces a novel approach to raise awareness of environmental issues through the delivery of personalized advice. The individuals' advice emerges from the use model and the surroundings. The results of this study illustrate a high user acceptance regarding the use of the mobile eco-app. Users indicated in their responses to the system's usefulness survey that the application provided a user-friendly and pleasant interface, while the advice received was pertinent, enjoyable, and useful. Moreover, the vast majority of users stated that they intend to use the application in future and recommend it to a friend. The feasibility and suitability of mobile eco-apps for improving users' environmental consciousness is also attested by $[8,10,49]$. These studies have highlighted the importance of exploiting mobile technologies to expose the community to environmental protection. Moreover, they have also confirmed that the use of mobile eco-apps had positive effect on users' awareness of sustainability issues and users enjoyed using such applications.

Regarding the personalization of the content provided in a mobile eco-app, our evaluation results reveal that combining a user model with context features (such as location, time, and season) can significantly improve users' environmental awareness. In particular, users' awareness on all the three environmental dimensions involved in the survey, namely conscious consuming, reducing waste/recycling, and energy saving, were increased around 20 units, reaching a percentage higher than $70 \%$. Triggering content at the right time and place and pushing notifications in terms of advisory service can increase the chances of engaging users in behavior change [50]. The findings are congruent with the research of $[51,52]$, which shows that personalized eco-feedback and interventions toward environmental issues using location tracking can promote environmental behavior and alter users' attitudes toward the protection of the ecosystem.

\section{Conclusions}

In this paper, the main purpose was to increase environmental awareness of smartphone users in a personalized way by combining AHP and PROMETHEE II. The mobile application contains a user model with different information, such as place of residence (e.g., city, mountain, sea, etc.), age, and user habits, such as waste management activities, natural resource conservation activities, general environmental protection activities, and biodiversity activities. After the initialization of the user model, the system uses AHP and PROMETHEE II to provide the user with recommendations to increase environmental awareness. The criteria, considered when evaluating environmental recommendations, include the compatibility of the user's current location, living environment, habits, interests, needs, age, and season.

AHP is one of the multi-criteria decision-making methods, which is powerful yet simple. AHP breaks complex decision-making problems into multiple hierarchical levels. 
The weights of each criterion and alternatives are evaluated in a pairwise comparison, and then priority is calculated.

PROMETHEE II is one of the most extensively studied and commonly used outranking methods, developed to solve problems of multiple criteria. The main reason for utilizing the PROMETHEE II method is that the particular model can be effectively implemented in the domain presented and all information gathered in the decision matrix can be completely and effectively calculated in making final decisions. Moreover, compared to other MCDM methods, PROMETHEE II is a fairly simple ranking method in concept and practice.

The combination of the aforementioned methods and theories makes decision-making more qualitative and thus it offers a more personalized experience to users, since they receive advice which is tailored to their needs and preferences in awakening their environmental awareness.

The evaluation results are very promising, showing a high degree of usability and acceptance of the developed application, which is due to the user-friendly interface, as well as the useful and suitable to user model advice. Moreover, the findings reveal that the proposed approach has significant impact on users' consciousness regarding environmental issues, leading to the improvement of environmental awareness regarding the conscious consuming, the reduction of waste and recycling, and energy saving.

Part of our future work is to extend the evaluation sample, including people from different ages, education levels, economic class, and geographic area, and enrich the evaluation procedure using the assessment of the user acceptance of the presented mobile application. Furthermore, it is in our plans to design a model with ensemble learning methods for decision making and the comparison of different MCDM approaches, being tailored to environmental awareness, to check their superiority.

Author Contributions: Conceptualization, A.K., K.K. and C.T.; methodology, A.K., K.K. and C.T.; software, A.K., K.K. and C.T.; validation, A.K., K.K. and C.T.; formal analysis, A.K., K.K. and C.T.; investigation, A.K., K.K. and C.T.; resources, A.K., K.K. and C.T.; data curation, A.K., K.K. and C.T.; writing - original draft preparation, A.K., K.K. and C.T.; writing—review and editing, A.K. and C.T.; visualization, A.K., K.K. and C.T.; supervision, K.K. and C.S. All authors have read and agreed to the published version of the manuscript.

Funding: This research received no external funding.

Data Availability Statement: The data, used to support the findings of this study, have not been made available because they contain information that could compromise research participant privacy/consent.

Conflicts of Interest: The authors declare no conflict of interest.

\section{References}

1. Huang, B.; Gan, M.; Ji, Z.; Fan, X.; Zhang, D.; Chen, X.; Sun, Z.; Huang, X.; Fan, Y. Recent progress on the thermal treatment and resource utilization technologies of municipal waste incineration fly ash: A review. Process Saf. Environ. Prot. 2022, 159, 547-565. [CrossRef]

2. Kuroda, K.; Otsuka, K.; Shimomura, Y. Environmental awareness about coastal area and behaviors of regional fish-eating. In OCEANS 2016-Shanghai; IEEE: Piscataway, NJ, USA, 2016; pp. 1-5. [CrossRef]

3. Cruz Shannon, M.; Manata, B. Measurement of Environmental Concern: A Review and Analysis. Front. Psychol. 2020, 11, 363. [CrossRef] [PubMed]

4. Janakiraman, S.; Watson, S.L.; Watson, W.R. Exploring the Effectiveness of Digital Games in Producing pro-Environmental Behaviors when Played Collaboratively and Individually: A Mixed Methods Study in India. TechTrends 2021, 65, 331-347. [CrossRef] [PubMed]

5. Kabassi, K.; Martinis, A. Studies for Designing Stereotypes in a Mobile Recommendation System for Environmental Awareness. In Proceedings of the 2020 15th International Workshop on Semantic and Social Media Adaptation and Personalization (SMA), Zakynthos, Greece, 29-30 October 2020; pp. 1-6. [CrossRef]

6. Krouska, A.; Troussas, C.; Sgouropoulou, C. Applying Genetic Algorithms for Recommending Adequate Competitors in Mobile Game-Based Learning Environments. In Intelligent Tutoring Systems. ITS 2020. Lecture Notes in Computer Science; Kumar, V., Troussas, C., Eds.; Springer: Cham, Switzerland, 2020; Volume 12149. [CrossRef] 
7. Tiron-Tudor, A.; Deliu, D. Reflections on the human-algorithm complex duality perspectives in the auditing process. Qual. Res. Account. Manag. 2021. [CrossRef]

8. Nadzir, M.M.; Seowfuddin, N.F.A.S. Reduce, Reuse, Recycle (3Rs) Awareness App: Mobile Learning Application for Supporting Environmental Awareness Initiatives. In Proceedings of the 2019 IEEE Conference on e-Learning, e-Management \& e- Services (IC3e), Pulau Pinang, Malaysia, 19-21 November 2019; pp. 31-34. [CrossRef]

9. Kuppusamy, S.; Mari, T. Relationship between environmental awareness and environmental knowledge using "AKASA" model among architecture students in private universities, Klang Valley, Malaysia. In Proceedings of the 2017 2nd International Conference on Knowledge Engineering and Applications (ICKEA), London, UK, 21-23 October 2017; pp. 151-155. [CrossRef]

10. Nunes, E.; Luz, A.R.; Lemos, E.M.; Maciel, C.; Dos Anjos, A.M.; Borges, L.C.L.F.; Nunes, C. Mobile serious game proposal for environmental awareness of children. In Proceedings of the 2016 IEEE Frontiers in Education Conference (FIE), Erie, PA, USA, 12-15 October 2016; pp. 1-8. [CrossRef]

11. Mohammed, A.A.; Dominic, D.D. Social Influence on the Use of Social Media Towards Environmental Sustainability Awareness in HEI. In Proceedings of the 2021 International Conference on Computer \& Information Sciences (ICCOINS), Kuching, Malaysia, 13-15 July 2021; pp. 294-299. [CrossRef]

12. Zhang, X.; Tao, Z. Two-stage supply chain optimization with consumers' environmental awareness under cap-and-trade regulation. In Proceedings of the 2020 Chinese Control and Decision Conference (CCDC), Hefei, China, 22-24 August 2020; pp. 1584-1589. [CrossRef]

13. Guo, S. Utilizing Digital Storytelling to Foster Pupil's Language and Environmental Awareness and Action. In Proceedings of the 2021 International Conference on Advanced Learning Technologies (ICALT), Tartu, Estonia, 12-15 July 2021; pp. 288-290. [CrossRef]

14. Velásquez, P.; Vásquez, L.; Correa, C.; Rivera, D. A low-cost IoT based environmental monitoring system. A citizen approach to pollution awareness. In Proceedings of the 2017 CHILEAN Conference on Electrical, Electronics Engineering, Information and Communication Technologies (CHILECON), Pucon, Chile, 18-20 October 2017; pp. 1-6. [CrossRef]

15. McGinity, M. Immersive Media for Environmental Awareness. In Proceedings of the 2018 IEEE Workshop on Augmented and Virtual Realities for Good (VAR4Good), Reutlingen, Germany, 18 March 2018; pp. 1-5. [CrossRef]

16. Teixeira, G.; Bremm, L.; Roque, A.d.S. Educational Robotics Insertion in High Schools to Promote Environmental Awareness about E-Waste. 2018 Latin American Robotic Symposium. In Proceedings of the 2018 Brazilian Symposium on Robotics (SBR) and 2018 Workshop on Robotics in Education (WRE), João Pessoa, Brazil, 6-10 November 2018; pp. 591-597. [CrossRef]

17. Zhu, Q.; Sarkis, J.; Lai, K. Regulatory Policy Awareness and Environmental Supply Chain Cooperation in China: A RegulatoryExchange-Theoretic Perspective. IEEE Trans. Eng. Manag. 2018, 65, 46-58. [CrossRef]

18. Kaiser, T.J.; LaMeres, B.J.; Buerkle, T.; Hogan, J.A.; Weber, R.J. Experimental Conformation of Ionizing Sensing for Space Radiation Environmental Awareness. IEEE Sens. J. 2016, 16, 3482-3483. [CrossRef]

19. Guo, H.; Lian, X.; Zhang, Y.; Ren, Y.; He, Z.; Zhang, R.; Ding, N. Analysis of Environmental Policy's Impact on Remanufacturing Decision Under the Effect of Green Network Using Differential Game Model. IEEE Access 2020, 8, 115251-115262. [CrossRef]

20. Alkawsi, G.A.; Ali, N.; Baashar, Y. An Empirical Study of the Acceptance of IoT-Based Smart Meter in Malaysia: The Effect of Electricity-Saving Knowledge and Environmental Awareness. IEEE Access 2020, 8, 42794-42804. [CrossRef]

21. IordachePlatis, M.; Romanowicz, J. Integrating Energy Saving Awareness into Student Engagement-Based Teaching and Learning Process. Sustainability 2020, 12, 9626. [CrossRef]

22. Andresen, E.; López-del-Toro, P.; Franquesa-Soler, M.; Mora, F.; Barraza, L. Teenagers' Awareness about Local Vertebrates and Their Functions: Strengthening Community Environmental Education in a Mexican Shade-Coffee Region to Foster Animal Conservation. Sustainability 2020, 12, 8684. [CrossRef]

23. Dalu, M.T.B.; Cuthbert, R.N.; Muhali, H.; Chari, L.D.; Manyani, A.; Masunungure, C.; Dalu, T. Is Awareness on Plastic Pollution Being Raised in Schools? Understanding Perceptions of Primary and Secondary School Educators. Sustainability 2020, 12, 6775. [CrossRef]

24. Ma, Y.; Men, J.; Cui, W. Does Environmental Education Matter? Evidence from Provincial Higher Education Institutions in China. Sustainability 2020, 12, 6338. [CrossRef]

25. Toljaga-Nikolić, D.; Todorović, M.; Dobrota, M.; Obradović, T.; Obradović, V. Project Management and Sustainability: Playing Trick or Treat with the Planet. Sustainability 2020, 12, 8619. [CrossRef]

26. Meschini, M.; Prati, F.; Simoncini, G.A.; Airi, V.; Caroselli, E.; Prada, F.; Marchini, C.; Machado Toffolo, M.; Branchini, S.; Brambilla, V.; et al. Environmental Awareness Gained During a Citizen Science Project in Touristic Resorts Is Maintained after 3 Years Since Participation. Front. Mar. Sci. 2021, 8, 584644. [CrossRef]

27. Daryanto, A.; Song, Z.; Soopramanien, D. The COVID-19 pandemic as an impetus for pro-environmental behaviours: The role of causal attribution. Pers. Individ. Differ. 2022, 187, 111415. [CrossRef]

28. Goranczewski, B.; Szeliga-Duchnowska, A. Motivational Impact of Environmental Management on the Environmental Awareness in a Workplace. Eur. Res. Stud. J. Eur. Res. Stud. J. 2021, 0, 443-455. [CrossRef]

29. Novotný, R.; Huttmanová, E.; Valentiny, T.; Kalistová, A. Evaluation of Environmental Awareness of University Students: The Case of the University of Presov, Slovakia. Eur. J. Sustain. Dev. 2021, 10, 59. [CrossRef]

30. Khoiri, A.; Sunarno, W.; Sajidan, S.; Sukarmin, S. Analysing students' environmental awareness profile using strategic environmental assessment. F1000Research 2021, 10, 305. [CrossRef] 
31. Handoyo, B.; Astina, I.K.; Mkumbachi, R.L. Students' environmental awareness and pro-environmental behaviour: Preliminary study of geography students at state university of malang, International Geography Seminar 2019. IOP Conf. Ser. Earth Environ. Sci. 2021, 683, 012049. [CrossRef]

32. Hsu, J.L.; Pivec, M. Integration of Sustainability Awareness in Entrepreneurship Education. Sustainability 2021, 13, 4934. [CrossRef]

33. Troussas, C.; Krouska, A.; Sgouropoulou, C. Enhancing Human-Computer Interaction in Digital Repositories through a MCDABased Recommender System. Adv. Hum.-Comput. Interact. 2021, 2021, 7213246. [CrossRef]

34. Chmielarz, W.; Zborowski, M. On the Assessment of e-Banking Websites Supporting Sustainable Development Goals. Energies 2022, 15, 378. [CrossRef]

35. Vinodh, S.; Jeya Girubha, R. PROMETHEE based sustainable concept selection. Appl. Math. Model. 2012, 36, 5301-5308. [CrossRef]

36. Sousa, M.; Almeida, M.F.; Calili, R. Multiple Criteria Decision Making for the Achievement of the UN Sustainable Development Goals: A Systematic Literature Review and a Research Agenda. Sustainability 2021, 13, 4129. [CrossRef]

37. Troussas, C.; Krouska, A.; Sgouropoulou, C. Improving Learner-Computer Interaction through Intelligent Learning Material Delivery Using Instructional Design Modeling. Entropy 2021, 23, 668. [CrossRef]

38. Saaty, T.L. The Analytic Hierarchy Process; McGraw-Hill: New York, NY, USA, 1980.

39. Saaty, T.; Hu, G. Ranking by Eigenvector versus Other Methods in the Analytic Hierarchy Process. Appl. Math. Lett. 1998, 11, 121-125. [CrossRef]

40. Brans, J.P. Lingenierie de la Decision. Elaboration Dinstruments Daide a la Decision, Methode PROMETHEE. In Laide a la Decision: Nature, Instruments et Perspectives Davenir; Nadeau, R., de Landry, M., Eds.; Universite Laval: Quebec, QC, Canada, 1982; pp. 183-214.

41. Brans, J.P.; Vincke, P. A Preference Ranking Organisation Method, (The PROMETHEE Method for Multiple Criteria DecisionMaking). Manag. Sci. 1985, 31, 647-656. [CrossRef]

42. Tiwari, N. Using the Analytic Hierarchy Process (AHP) to identify Performance Scenarios for Enterprise Application. Comput. Measurement Group Meas. It 2006, 4.

43. Abedi, M.; Torabi, S.A.; Norouzi, G.-H.; Hamzeh, M.; Elyasi, G.-R. PROMETHEE II: A knowledge-driven method for copper exploration. Comput. Geosci. 2012, 46, 255-263. [CrossRef]

44. Vahid, B.; Zahraie, B.; Roozbahani, A. Comparison of AHP and PROMETHEE Family Decision Making Methods for Selection of Building Structural System. Am. J. Civ. Eng. Archit. 2014, 2, 149-159.

45. Goswami, S.S. Outranking Methods: Promethee I and Promethee II. Found. Manag. 2020, 12, 93-110. [CrossRef]

46. Singh, A.; Gupta, A.; Mehra, A. Best criteria selection based PROMETHEE II method. OPSEARCH 2020, 58, 160-180. [CrossRef]

47. Zhu, $\Upsilon$.; Buchman, A. Evaluating and Selecting Web Sources as External Information Resources of a Data Warehouse. In Proceedings of the Third International Conference on Web Information Systems Engineering (WISE'00), Singapore, 14 December 2000; pp. 149-160.

48. Siraj, S.; Mikhailov, L.; Keane, J.A. PriEsT: An interactive decision support tool to estimate priorities from pairwise comparison judgments. Int. Trans. Opt. Res. 2015, 22, 217-235. [CrossRef]

49. Turan Çimşir, B.; Uzunboylu, H. Awareness Training for Sustainable Development: Development, Implementation and Evaluation of a Mobile Application. Sustainability 2019, 11, 611. [CrossRef]

50. Typhina, E. Designing eco-apps to engage adult learners. In Proceedings of the 2015 International Conference on Interactive Mobile Communication Technologies and Learning (IMCL), Thessaloniki, Greece, 19-20 November 2015; IEEE: Piscataway, NJ, USA; pp. 83-87.

51. Bucher, D.; Mangili, F.; Cellina, F.; Bonesana, C.; Jonietz, D.; Raubal, M. From location tracking to personalized eco-feedback: A framework for geographic information collection, processing and visualization to promote sustainable mobility behaviors. Travel Behav. Soc. 2019, 14, 43-56. [CrossRef]

52. Inyim, P.; Batouli, M.; Reyes, M.P.; Carmenate, T.; Bobadilla, L.; Mostafavi, A. A smartphone application for personalized and multi-method interventions toward energy saving in buildings. Sustainability 2018, 10, 1744. [CrossRef] 